\title{
EL DERECHO CONSTITUCIONAL Y LOS TEXTOS PARA SU ENSEÑANZA. A PROPOSITO DEL DIRITTO COSTITUZIONALE DE GIUSEPPE DE VERGOTTINI
}

\author{
PABLO LUCAS MURILLO DE LA CUEVA \\ Catedrático de Derecho Constitucional \\ Magistrado del Tribunal Supremo
}

SUMARIO

I. Algo más que un manual de Derecho constitucional. II. Los textos para la enseñanza del Derecho político. III. Por una nueva generación de manuales de Derecho constitucional.

\section{ALGO MÁS QUE UN MANUAL DE DERECHO CONSTITUCIONAL}

En el otoño de 2017 se ha publicado una nueva edición del Diritto costituzionale de Giuseppe de Vergottini (Wolters Kluwer-Cedam, Padua, 958 págs.). Es la novena desde la aparición de la primera en 1997. Conocía esas anteriores versiones, no obstante, en esta ocasión nada más verlo me vino a la memoria el texto que tuve que estudiar en 1977, cuando seguía en la Facultad de Derecho de la Universidad de Bolonia el curso de Derecho constitucional. Se trataba de las Istituzioni di Diritto Pubblico de Costantino Mortati que — casualidad- en su novena edición ya contaban con 1574 páginas repartidas en dos volúmenes (Cedam, Padua, 1975 y 1976). La editorial ha conservado el mismo diseño de la cubierta y la apariencia de sus manuales con la única diferencia del color de las franjas superior e inferior, antes verde ahora azul. Naturalmente, el recuerdo no se debió sólo al aspecto externo.

Las Istituzioni de Mortati fueron para mí entonces y durante mucho tiempo después la primera fuente a la que acudir para encontrar orientación e información ya fuera para preparar las explicaciones a los alumnos de licenciatura, ya fuera a la hora de buscar materiales para elaborar mis trabajos. Pensadas y escritas inicialmente para el alumno italiano al modo de lecciones, pronto adquirieron una dimensión y relevancia muy superiores ya que en sus páginas no sólo se ofrecía una explicación elemental sino que se incluían además los principales desarrollos que 
habían experimentado y se daba noticia de lo que de importante se había escrito sobre cada uno de los asuntos tratados. Desde la noción de ordenamiento jurídico y de Estado, con sus elementos y formas, al concepto de Constitución y su plasmación en la historia política de Italia. A partir de ahí, se adentraban en el examen detenido de la regulación de los órganos previstos por la Constitución y de las relaciones que deben mantener unos con otros, para abordar después el régimen de las autonomías territoriales y de los derechos y terminar con lasgarantías jurisdiccionales y formales del conjunto del ordenamiento constitucional.

Podía decirse que todo estaba allí y no sólo el alumno encontraba el material sobrado para preparar sus exámenes sino que el investigador postgraduado sabía que eran una fuente segura de conocimiento y de referencias bibliográficas y jurisprudenciales para profundizar en cualquier aspecto del Derecho constitucional e, incluso, del Derecho público porque, es verdad, las Istituzioni de Mortati, como indica su título, se extendían más allá de los confines del Derecho constitucional. Eran, en definitiva, una obra que no tenía igual en la literatura académica del país transalpino.

Ahora, el Diritto costituzionale de Giuseppe de Vergottini, notablemente ampliado en su última versión, ofrece esas utilidades y creo que aporta otras que refuerzan su valor. Dentro de los límites que permite una materia cuyos contornos están esencialmente definidos, sigue un planteamiento diferente y, como es natural, responde al estilo y a la formación propios del autor y a las distintas circunstancias existentes en Italia, en Europa y en el mundo cuando se ha escrito y en el momento de poner al día las sucesivas ediciones.

En efecto, en los más de cuarenta años que han transcurrido desde que estudié las Istituzioni de Mortati y la aparición de esta última edición del manual de Giuseppe de Vergottini, la Constitución italiana ha experimentado cambios de relieve. Además de otras modificaciones puntuales, la de 2001 supuso una importante reforma del Estado regional construido a partir de las previsiones del texto de 1947, especialmente desde de los años setenta del siglo pasado cuando las mayorías de centro izquierda sumaron las regiones de estatuto ordinario a las de estatuto especial formadas en los primeros años de vida de la República. Otra modificación más profunda no ha prosperado al fracasar el referéndum del 4 de diciembre de 2016. En el proceso que llevó a él se pusieron de manifiesto los aspectos del ordenamiento constitucional que, en opinión de muchos expertos y ante la experiencia adquirida, deben revisarse y en coherencia, las cámaras aprobaron un texto que, entre otras novedades de relieve, suponía un nuevo sistema electoral, el abandono del bicameralismo perfecto, la reducción sustancial del número de senadores, la introducción del referéndum propositivo, la supresión de Consejo Nacional de la Economía y el Trabajo, una notable recuperación por el Estado de competencias ahora en manos de las regiones y la supresión de las provincias. El esfuerzo desplegado para plasmar en un proyecto esas modificaciones y el importante apoyo, aunque no fuera suficiente, que logró esta iniciativa, hacen que no deba descartarse que se retome en el futuro en todo o en parte. 
No se deben olvidar, por otra parte, las consecuencias del impacto que produjo el fenómeno denominado Tangentopoli y el que se ha descrito como tránsito de la primera a la segunda República. Aunque no se ha producido desde el punto de vista constitucional, el sistema político es ahora si cabe más complejo porque al bipartidismo imperfecto le ha sustituido una nueva correlación de fuerzas políticas todavía más dispersa en cuya génesis han jugado también un papel determinante los efectos de la crisis económica general en la que todavía nos encontramos. El caso es que han desaparecido los partidos que protagonizaron las primeras décadas de la experiencia republicana, a la derecha y a la izquierda reina la división y han entrado en escena o se han fortalecido otros de sesgo populista. También ha hecho acto de presencia una formación «antipolítica» que ha obtenido una notable representación en el Parlamento y en otras sedes de manera que, esto no es una novedad, resulta sumamente difícil articular mayorías que gobiernen.

Las reformas de la Constitución que se han materializado, las deficiencias que se han querido corregir con la que fracasó el 4 de diciembre de 2016, los condicionamientos derivados del nuevo abanico de fuerzas políticas y la praxis constitucional que se lleva a cabo en este complicado panorama han sido tenidos en cuenta en las páginas de este libro. Asimismo, se encuentran en él las referencias imprescindibles a la condición Italia de miembro integrante de la Unión Europea y a las consecuencias que implica el ejercicio por las instituciones europeas de competencias derivadas de la Constitución. En fin, como es natural, no podían pasar desapercibidas las transformaciones de todo orden derivadas de la llamada globalización.

Pocos pueden estar en mejor posición que Giuseppe de Vergottini, profundo conocedor de las instituciones y mecanismos constitucionales, para apreciar el impacto de las nuevas circunstancias internas y externas. Recordemos que, entre otras muchas publicaciones, es autor también del Diritto costituzionale comparato (Cedam, Padua, 2013, 772 págs.), cuya primera edición de 1981 tradujo e introdujo Pablo Lucas Verdú (Derecho Constitucional Comparado, Espasa, Madrid, 1983) mientras que la sexta fue traducida por Claudia Herrera (Editorial Universidad, Buenos Aires, 2005) y ha alcanzado ya otras nueve ediciones. Es una obra que le acredita como comparatista de primer nivel, tal como es reconocido internacionalmente. Desde esa condición tiene especial autoridad para recordarnos, además, que las diversas soluciones a las que se ha recurrido y se recurre para regular la organización y el ejercicio del poder y para limitarlo a fin de garantizar los derechos de las personas, solamente pueden comprenderse si se tienen presentes los presupuestos culturales desde los que parten y, naturalmente, la realidad social y política en la que actúan.

La singularidad de la contribución de Giuseppe de Vergottini consiste en que ha sabido conservar la aproximación jurídica que ha caracterizado a la escuela italiana del Derecho Público desde que Vittorio Emanuele Orlando estableciera los criterios técnicos para reconstruirlo y, al mismo tiempo, combinarla con las aportaciones de los historiadores y de los politólogos y con la observación de la 
vida de las normas. El resultado es una clara explicación del ordenamiento constitucional tal como está conformado y tal como se manifiesta en la práctica cotidiana. La visión que ofrece del Estado y de su organización y funcionamiento no es, pues, meramente formal sino real porque capta su dinámica, la que le imprimen los actores que protagonizan desde dentro y desde fuera de las instituciones la vida política. Ciertamente, habla de la italiana pero sus observaciones sobre la manera en que los operadores jurídicos y los sujetos políticos inciden en la efectividad de la Constitución y del Derecho que preside son útiles para todos los ordenamientos que comparten los mismos fundamentos, en especial para el nuestro en tiempos en que se debate sobre su posible reforma.

Este libro, tras introducirnos en el Derecho de la Constitución, lo sitúa en el contexto determinado por el ordenamiento de la comunidad internacional, por el de la Unión Europea y por el del Estado, cuyos elementos y formas analiza. A partir de ahí se ocupa de las fuentes normativas para adentrarse luego en la posición de la persona y en la de las formaciones sociales. En este punto desarrolla un completo estudio de los principios, derechos y deberes. Establecido el estatuto de los individuos y de los grupos en los que desenvuelven su personalidad, se ocupa de los mecanismos de relación entre la sociedad y la organización constitucional, es decir, las elecciones y los institutos de democracia directa, antes de exponer el régimen del Parlamento y sus funciones legislativa y de dirección y control político. A continuación, trata del Presidente de la República y, una vez examinados los rasgos que caracterizan a la jefatura del Estado, se dedica al Gobierno y a la Administración Pública estatal. Al estudio de estas estructuras sigue el de los órganos auxiliares del poder ejecutivo. El análisis de la organización del Estado termina con la Magistratura, primero, y con la Corte Constitucional después. Por último, trata de las autonomías territoriales, esto es, de las regiones y de los municipios y de las provincias.

En la exposición de cada uno de los extremos en que se descomponen esas cuestiones, explica los preceptos constitucionales, legales o reglamentarios correspondientes y la jurisprudencia y la praxis cuando es del caso. Unas notas orientadoras sobre el uso del manual, un amplio y seleccionado apéndice bibliográfico y un completo índice analítico cierran el volumen, cuyas páginas contienen en el margen ladillos que identifican el concreto concepto que se está abordando en ellas para hacer más fácil al lector situarse y localizar lo que le interesa.

En conjunto, dedica una atención equilibrada a las variadas materias de las que se ocupa. Además, al igual que sucede en sus otros libros y artículos, Giuseppe de Vergottini, al elaborar este Diritto costituzionale no se ha encerrado en la doctrina de su país aunque, por su variedad y riqueza le habría ofrecido suficiente fundamento, sino que se ha servido también de fuentes bibliográficas de diferentes procedencias nacionales. Por eso, a la hora de establecer los conceptos, identificar los principios y analizar las instituciones, sus órganos y relaciones, cuenta con una perspectiva muy amplia que le permite llegar a conclusiones de gran valor. 


\section{LOS TEXTOS PARA LA ENSEÑANZA DEL DERECHO POLÍTICO}

Este Diritto costituzionale, aunque ya es mucho más, se ha publicado en la colección de «Manuales de Ciencias Jurídicas» creada en su día por la Editorial Cedam. Los manuales son instrumentos indispensables para la enseñanza de una materia pero, a diferencia de lo sucedido en otras disciplinas, en España no abundaron en la de Derecho político, denominación tradicional, sustituida a mediados de los años ochenta del pasado siglo por la de Derecho constitucional, y tampoco abundan ahora en esta última.

El Derecho político estudiaba, entre otras cosas, la organización y el ejercicio del poder político y los derechos y deberes de las personas, por tanto, se ocupaba de la Constitución. A partir de 1939 España dejó de tener Constitución y quedó sometida a un régimen de dominación política que descansaba en el poder personal del Caudillo y en las instituciones formadas en torno a él. Aunque se publicaron textos explicando el contenido de las Leyes Fundamentales que daban forma a esa situación, fueron muy pocos los autores que se adentraron en la exposición sistemática de las características jurídicas de un régimen que nació negando los principios del constitucionalismo democrático y se asentó hasta el final en la unidad de poder. Debe tenerse en cuenta, además, que no era posible explicarlo desde postulados no ya democráticos, sino simplemente críticos pues no existía libertad de expresión ni de cátedra y, si se cuestionaban sus fundamentos, se corría el riesgo cierto de sufrir sanciones penales o administrativas.

En estas condiciones, se ha recordado muchas veces, la mayoría de los profesores de Derecho político optó por ocuparse de los contenidos no jurídicos que se venían reuniendo en esa disciplina y le habían dado carácter enciclopédico. Quienes prefirieron mantenerse en el campo del Derecho constitucional lo hicieron explicando las Constituciones que han ejercido más influencia y los elementos que les resultan comunes o por cultivar la historia del constitucionalismo. A partir de los años cincuenta se publicaron obras importantes en esos campos. Me limitaré a recordar, de las que se mantuvieron en el núcleo del Derecho político, algunas de las principales.

Así, el Derecho constitucional comparado de Manuel García Pelayo (Revista de Occidente, Madrid, 1950) ejerció gran influencia. Luis Sánchez Agesta, autor de unas Lecciones de Derecho Político (Granada, 1943-1945) y de la Historia del constitucionalismo español (Instituto de Estudios Políticos, Madrid, 1955), publicó un Curso de Derecho Constitucional Comparado (Facultad de Derecho. Universidad Complutense, Madrid, 1963) y, posteriormente, los Principios de Teoría Política (Editora Nacional, Madrid, 1970). Alcanzaron gran eco las diversas ediciones del libro de Manuel Jiménez de Parga Los regímenes políticos contemporáneos (Tecnos, Madrid, 1959). Y los tres volúmenes de los Principios de Ciencia Política (Tecnos, Madrid, 1967, 1969 y 1971) y los tres primeros del Curso de Derecho Político de Pablo Lucas Verdú (Tecnos, Madrid, 1972, 1974 y 1976), el cuarto se publicó en 
1984, ya tras varios años de vigencia de la Constitución, aportaron un nuevo enfoque. Inspirados en una concepción democrática y sustentados en un importante y actual en aquellos momentos aparato bibliográfico, abrieron perspectivas a alumnos e investigadores. Ya en plena transición vio la luz el Tratado de Derecho Político de Nicolás Pérez Serrano (Civitas, Madrid, 1976). Es un libro valioso que recoge diversos trabajos suyos reunidos por su hijo Nicolás Pérez-Serrano Jáuregui. Ahora bien, fueron escritos entre 1936 y 1939 y, por tanto, no es representativo de la actitud evasiva a la que me estoy refiriendo salvo por el hecho de que no se hubiera publicado antes.

Esa huida académica del Derecho de las Leyes Fundamentales condujo igualmente a que se tradujeran y utilizaran en las Facultades españolas manuales de otros países.

En efecto, Pablo Lucas Verdú tradujo e introdujo la edición italiana de 1962 del Diritto costituzionale de Paolo Biscaretti di Ruffia (Tecnos, Madrid, 1965), con cuya sistemática guarda cierta semejanza el de De Vergottini. Más tarde, profesores de la Universidad de Barcelona tradujeron dos manuales franceses importantes. Me refiero a las Instituciones políticas y Derecho constitucional de Maurice Duverger (Ariel, Barcelona, 1970). Introducidas por Pablo Lucas Verdú, su traducción y adaptación fueron dirigidas por Jordi Solé Tura que añadió un estudio sobre el régimen político franquista luego sustituido en la edición de 1979 por un capítulo dedicado ya a la Constitución de 1978 de Miguel Ángel Aparicio Pérez. Algo parecido sucedió con el Derecho Constitucional e instituciones políticas de André Hauriou (Ariel, Barcelona, 1971), traducido y adaptado por José Antonio González Casanova que añadió un apéndice sobre el régimen franquista y en la edición de 1980 ya pasó a tratar de la Constitución. Poco después, Ramón Falcón Tella tradujo el Derecho Constitucional e instituciones políticas de Georges Burdeau (Editora Nacional, Madrid, 1981) que se publicó con un prólogo de Raúl Morodo.

Aunque no es propiamente un manual sino una obra dotada de mayor profundidad, se puede recordar que años antes se había traducido la Teoría de la Constitución de Karl Loewenstein (Ariel, Barcelona, 1964) por Alfredo Gallego Anabitarte quien escribió un importante estudio sobre Constitución y política a propósito de la obra de este autor. El Derecho político de Ekkehart Stein (Aguilar, Madrid, 1973), traducido por Fernando Sáinz Moreno y con una nota preliminar de Francisco Rubio Llorente y Gobierno constitucional y democracia de Carl Joachim Friedrich, traducido por Agustín Gil Lasierra (Instituto de Estudios Políticos, Madrid, 1975), se añadieron a este conjunto de textos extranjeros que en el período final del franquismo ayudaron a formar en los fundamentos del Derecho constitucional y de la democracia representativa a la mayor parte de quienes se ocuparían de estudiar, explicar y aplicar el ordenamiento que pasó a presidir la Constitución de 1978. Así, esta enseñanza y la ofrecida por las obras de los profesores españoles que explicaron la Teoría del Estado y de la Constitución y las instituciones que la garantizan ayudaron al buen fin de la transición democrática. 


\section{POR UNA NUEVA GENERACIÓN DE MANUALES DE DERECHO CONSTITUCIONAL}

Ya en vigor la Constitución de 1978 se han publicado numerosos estudios de muy diversa naturaleza sobre ella. Desde los comentarios sistemáticos de su articulado hasta monografías sobre sus distintos contenidos. Y, naturalmente, se han publicado también manuales. Algunos obra de varios autores y otros escritos por uno solo. No es mi propósito referirme a ellos en particular porque solamente me interesa ahora destacar que ni antes de la Constitución, ni después de su entrada en vigor y ni siquiera ahora cuando nos acercamos a la celebración de su cuadragésimo aniversario, hemos contado, contamos, con textos como aquellas Istituzioni de Mortati o este Diritto Costituzionale de Giuseppe de Vergottini.

Los que existen tienen un carácter esencialmente didáctico y, en ese sentido, responden plenamente a la finalidad propia de un manual. Son, pues, instrumentos de estudio para los alumnos que descargan a los profesores de las limitaciones que imponen la distribución de la carga lectiva y los horarios pero no profundizan más que lo indispensable en los temas y limitan la información bibliográfica y jurisprudencial a la imprescindible para el nivel de conocimientos que han de adquirir los estudiantes de grado. No han dado el paso de añadir contenidos más específicos, de subir el nivel de tratamiento de los aspectos principales y ofrecer así, además de las explicaciones elementales, un panorama amplio, comprensivo de las implicaciones de los principios, instituciones y derechos singulares objeto de examen.

Si antes de 1978 era explicable esa carencia, no lo es ahora. No sólo disponemos ya de una experiencia dilatada en la que se ha producido un intenso desarrollo de la Constitución y una variada jurisprudencia que ha contribuido a preservar su supremacía y a adaptar sus preceptos a las nuevas circunstancias que trae consigo el transcurso del tiempo. Es la nuestra una Constitución con prestigio fuera de España y con la que se identifica la amplia mayoría de los españoles aunque hayan aparecido en los últimos años, como decía antes, propuestas encaminadas a reformarla para preservar mejor sus principios y también quienes, desde una perspectiva radicalmente opuesta, la cuestionan sencillamente porque aspiran a separar una parte del resto del país o porque entienden que no responde debidamente al principio de la soberanía popular que sin embargo proclama.

En este tiempo se han formado nuevas generaciones de estudiosos del Derecho público en general y del Derecho constitucional en particular que se han unido a las de quienes vivieron la transición política y el proceso constituyente. Todos juntos representan una doctrina, no uniforme pues, como es natural, hay en ella diferentes orientaciones, pero sí caracterizada por un alto nivel de conocimientos, capacidad de análisis y de valoración. Las cada vez más abundantes publicaciones producidas por sus integrantes lo demuestran y confirman cada 
día. Es un nivel perfectamente equiparable al de las escuelas de los países europeos con los que habitualmente nos comparamos. Esto no sucedía en el período anterior a la Constitución en el que eran muy pocos los que se dedicaban a esta materia y menos aún los que de ellos podían compararse con sus colegas de más allá de los Pirineos.

Libros como el de Giuseppe de Vergottini son expresión de la madurez del autor pero se explican también en el contexto de la cultura jurídica en la que surgen y se encuadran y, ciertamente, expresan a su vez el grado de desarrollo que ha alcanzado al tiempo que coadyuvan a conformarla. No son ni pueden ser ajenos a ella. Es una cultura presidida por las ideas que informan al constitucionalismo, inclinada a la creación de condiciones reales de libertad e igualdad y volcada en la reflexión atenta sobre la técnica jurídica idónea para hacerlas efectivas. En otras palabras, se inscribe en la línea de pensamiento que aboga por la limitación del poder y la garantía de los derechos fundamentales y propugna la democracia representativa como la forma política que mejor sirve, según demuestra la historia, a la construcción y preservación de un orden de convivencia basado en aquellos valores.

Participamos de ese ambiente cultural y somos plenamente capaces de extraer de él las indicaciones y orientaciones necesarias para no solo conocer, comprender y exponer sino también para corregir las insuficiencias y defectos de nuestro ordenamiento constitucional y perfeccionar aquellas de sus regulaciones más logradas. En este sentido, me parece que desde hace tiempo existen en España las condiciones necesarias para superar la fase de los manuales meramente didácticos y contar con los que, como hace el de Giuseppe de Vergottini, a la descripción y calificación de principios, instituciones y derechos, sumen una consideración detenida allí donde sea precisa y suministren información sobre la jurisprudencia y la doctrina relevantes en torno a las cuestiones suscitadas.

Giuseppe de Vergottini ofrece un buen ejemplo de cómo se puede alcanzar satisfactoriamente ese objetivo pero no tiene que ser su libro el único modelo a seguir. Importa, sin embargo, reparar en que muestra una manera de reunir y exponer con equilibrio y proporción el saber jurídico adquirido sobre la ordenación del poder político y su virtualidad real. Es, pues, un buen acicate para animarnos a completar nuestra doctrina constitucional. Además del valor que en sí mismo han de tener obras de este tipo y del servicio que prestarán a alumnos e investigadores, creo que en las circunstancias en las que nos encontramos serían de gran utilidad para el debate entablado sobre si se debe o no reformar la Constitución y, desde luego, para defenderla frente a quienes propugnan su ruptura o su sustitución. 
TITLE: Constitutional Law, and the handbooks for its teaching. On Giuseppe de Vergottini's Diritto constituzionale.

Aвstract: Published in autumn 2017, the 9th edition of Giuseppe de Vergottini's Diritto costituzionale, a comprehensive and up to date study of italian Constitutional Law, is not only useful for professors and students but also for researchers. It is an achieved example of today's handbooks on the subject.

Resumen: Publicada en otoño de 2017, la 9a edición del Diritto costituzionale de Giuseppe de Vergottini, un completo y puesto al día tratado de Derecho constitucional italiano, no sólo es un texto útil para profesores y alumnos sino también para los investigadores. Es un logrado ejemplo de manual de nuestros días sobre esa materia.

KEY WORDS: Constitutional Law, teaching, handbooks

Palabras Clave: Derecho constitucional, enseñanza, manual.

FECHA DE RECEPCIÓN: 01.12.2017

FECHA DE ACEPTACIÓN: 01.02.2018 
